\title{
Study on Dynamic Response of Assembly Type Gear-Rotor System
}

\author{
Jishuang Dai ${ }^{\mathrm{a}}$, Peng Zhang ${ }^{\mathrm{b}}$, Chaofeng $\mathrm{Li}^{\mathrm{c}}$, Bo Wang ${ }^{\mathrm{d}}$ and Bangchun Wen ${ }^{\mathrm{e}}$
}

School of Mechanical Engineering \& Automation, Northeastern University, Shenyang, China

adaijs64@163.com, 'bhangpeng19850617@163.com, ${ }^{c}$ chfli@mail.neu.edu.cn,

dwangboblue1113@163.com, ${ }^{\mathrm{e}} \mathrm{bcwen1930@sina.com}$

\section{Key words: Assembled, Compressor, Gear, Rotor system, Dynamic response}

\begin{abstract}
The dynamic model of a rotor system of assembled compressor is established. Based on the single axis analysis, and considering the tilting-pad bearing stiffness characteristics with speed variations, the paper analyses whole system's nature characteristic with gearing mesh factors. It mainly expands with the form of amplitude-frequency drawing and spectrum charts, and examines the dynamic response with each key position of coupled systems under the two working conditions. The results show that, because of the existence of gear meshing effect, Low speed axis and high-speed axis in the corresponding speed shaft appeared a few larger vibration amplitudes, at high speed axis add unbalance force, can arouse resonance of this axis in the first two order critical speed, but in the other axis don't have obvious display.
\end{abstract}

\section{Introduction}

In the high-speed rotating machinery systems the gear coupling of rotor bearing system is abound, and such rotating machinery is developing to high speed, large-scale and systematic. At present, the design and manufacture of such assembled compressor in china often abnormal vibration and sometimes even had a serious accident of off-axis during the work process. In the past, this type of rotor system design has been widely used the method of design the rotor alone. This method ignores the coupling between the rotor and the practice of forced separation. It is not fully reflects the dynamics of such a rotor system. In addition, in the past the inherent characteristics of the system to calculate stiffness of the bearing support is often regarded as fixed amount. This is contrary to the lubricated bearings supporting stiffness characteristics, which change with the speed, and the calculated results will be inaccurate. It is essential to the characteristics of modular multi-rotor system have more comprehensive study.

This paper mainly studies the dynamic response of the coupled rotor problems. It mainly with the form of amplitude-frequency drawing and spectrum charts, and examines the dynamic response with each key position of coupled systems under two working conditions, which summarized the response of the coupled system.

\section{Assembled rotor system support and engagement model}

Fig. 1 shows an assembly compressor gear-rotor-bearing system of architecture diagram.G1 gear is the sprocket gear.G2 and G3 gears are driven gears. At the vicinity of each axis are installed support bearings and at both ends of the driven shaft installed semi-open impeller. Among them, driving shaft is low speed axial (LS), driven shaft is high speed axial (HS1, HS2). 


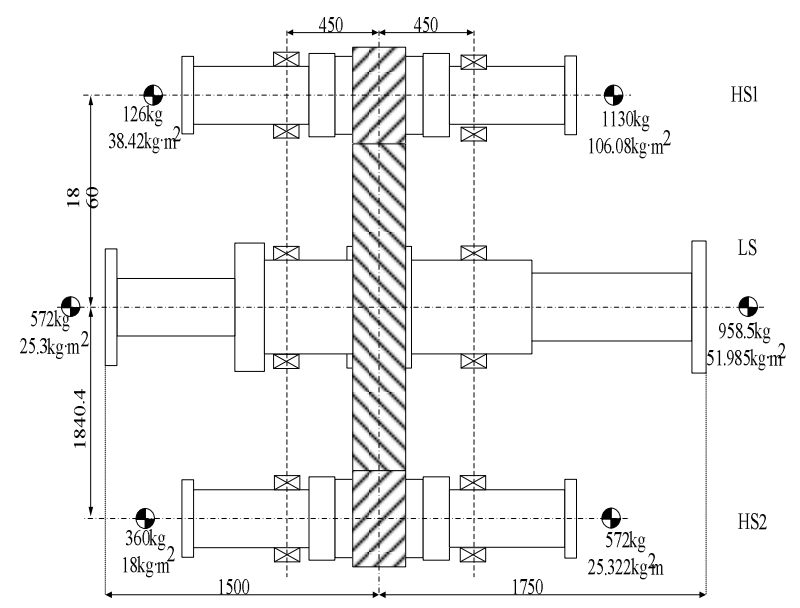

Fig. 1. An assembly compressor rotor diagram system of architecture

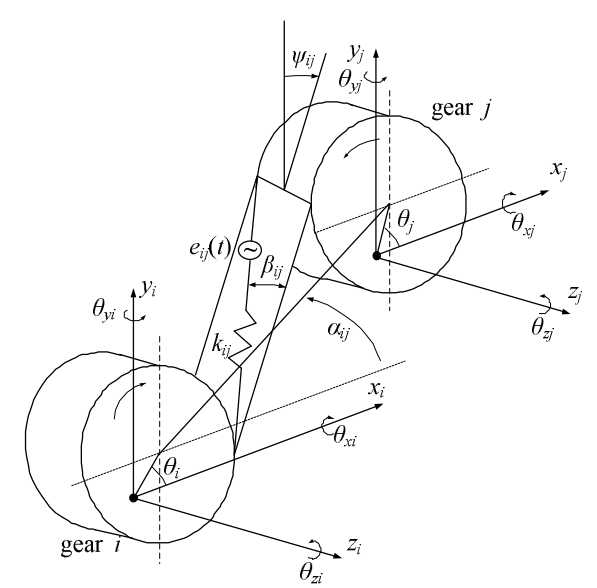

Fig. 2. A pair of gears dynamic mode

The structural parameters of the system. The structure parameters are as follows: LS-axis length is $L 1=3732.6 \mathrm{~mm}$, HS1-axis length is $L 2=2103.9 \mathrm{~mm}$,HS2-axis length is $L 3=1981.2 \mathrm{~mm}$, the bearing span is $l_{1}=900 \mathrm{~mm}, l_{2}=900 \mathrm{~mm}, l_{3}=875 \mathrm{~mm}$, the normal pressure angle of three gears $\alpha=20^{\circ}$, helix angle $\beta=14^{\circ}$. G1 gear direction of rotation is left-lateral, pitch circle diameter is $D 1=3278.311 \mathrm{~mm}$, gear number is $n_{1}=334, \mathrm{G} 2$ gear direction of rotation is right-lateral, pitch circle diameter is $D 2=402.434 \mathrm{~mm}$ gear number is $n_{2}=41$, G3 gear direction of rotation is right-lateral, pitch circle diameter is $D 3=441.689 \mathrm{~mm}$, gear number is $n_{3}=45$. The weight of the first impeller is $m_{1}=1130 \mathrm{~kg}$, polar moment of inertia is $J_{p 1}=106.68 \mathrm{~kg} \cdot \mathrm{m}^{2}$, The weight of the second impeller is $m_{2}=848.8 \mathrm{~kg}$, polar moment of inertia is $J_{p 2}=38.4 \mathrm{~kg} \cdot \mathrm{m}^{2}$, The weight of the third impeller is $m_{3}=427.7 \mathrm{~kg}$, polar moment of inertia is $J_{p 3}=23.39 \mathrm{~kg} \cdot \mathrm{m}^{2}$, The weight of the fourth impeller is $m_{4}$ $=360 \mathrm{~kg}$, polar moment of inertia is $J_{p 4}=18 \mathrm{~kg} \cdot \mathrm{m}^{2}$

LS-axis bearing width-radius ratio $L / D=0.5$, clearance ratio $\delta_{\max }=0.4 \mathrm{~mm} \quad \delta_{\max }=0.48 \mathrm{~mm}$. HS1 axis bearing width-radius ratio $L / D=1.0$, clearance ratio $\delta_{\min }=0.328 \mathrm{~mm}, \delta_{\max }=0.397 \mathrm{~mm}$. HS2 axis bearing width-radius ratio $L / D=0.7, \delta_{\min }=0.328 \mathrm{~mm}, \delta_{\max }=0.397 \mathrm{~mm}$.

The gear pairs of meshing force. For the dynamic system shown in Fig.1, which is used finite element ideas to discrete and each node has six degrees of freedom (show as Fig.2). Ignore gear's variety of omission error and tooth surface friction. The gear of meshing force related to the vibration displacement and vibration velocity besides the gear tooth bending rigidity and others structure parameters. Therefore, a pair of gears system has 12 degrees of freedom. Its equations of motion are given by literature references [1].

\section{The dynamic model of a rotor system is established}

The finite element model of rotor system shown as Fig.4, It mainly adopts isoparametric beam element and particle unit and ignore axial vibration every nodes have $x, y, z, 3$ directions of translation and rotation and 6 degrees of freedom. Each unit has 12 degrees of freedom. Unit of gear meshing stiffness shown in Fig. 4 is solved in 1.1. Support stiffness of bearing is solved in 1.2. It's a physical quantity changed with the rotating speed. The equation of the dynamic finite element system can be described as follows:

$$
M X+C X+K X=F(X, X)+R(t)+G
$$


In which $\boldsymbol{C}=(\boldsymbol{D}+\boldsymbol{J} \cdot \boldsymbol{\Omega}), \boldsymbol{X}=\left[q_{1} q_{2}, q_{\mathrm{n}}\right]^{T}(\mathrm{n}=14), \quad q_{i}=\left[x_{1}, y_{1}, \theta_{x i}, \theta_{y i}\right],(i=1,2, \ldots, 14) \cdot \boldsymbol{M}$ is the mass matrix of system , $\boldsymbol{C}$ is damping matrix , $\boldsymbol{D}$ is damp matrix of material damping $\boldsymbol{C}$ is gyroscopic matrix, $\boldsymbol{\Omega}$ is rotation speed, $\boldsymbol{K}$ is stiffness matrix, $\boldsymbol{F}$ is vector of bearing supporting force, $\boldsymbol{R}$ is unbalanced force, $\boldsymbol{G}$ is gravity vector of system, $\boldsymbol{X}$ is displacement vector of system , $\boldsymbol{M}, \boldsymbol{C}, \boldsymbol{J}, \boldsymbol{K}$ expression of units are given by literature references[3]

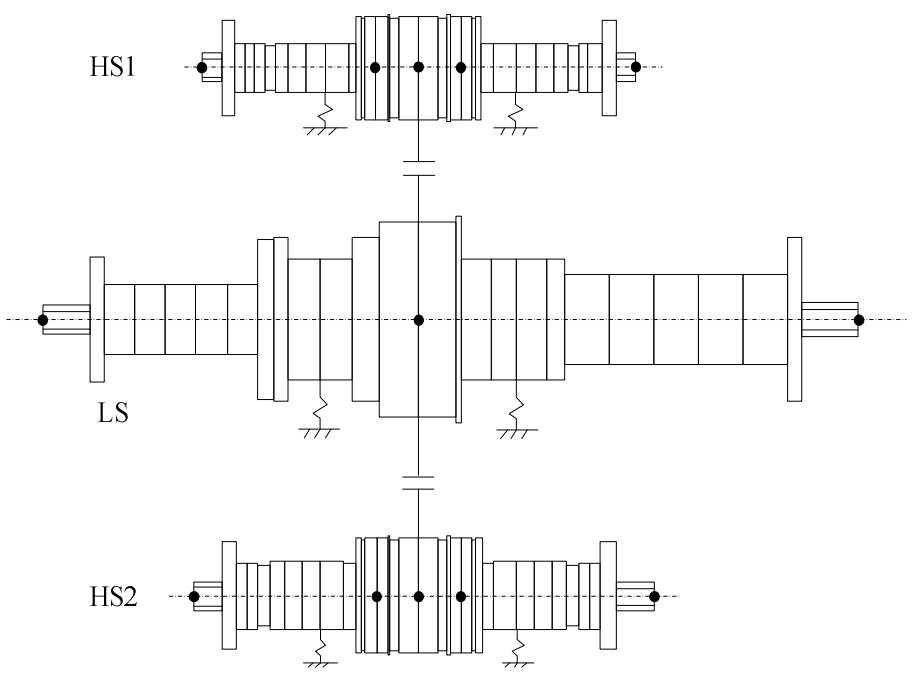

Fig. 4. Schematic diagram of whole machine unit divided

Low-speed shaft LS is divided into 26 units and 27 nodes, there are 3 mass elements respectively loading on nodes 1, 14, 27. High-speed shaft HS1 is divided into 35 units and 36 nodes. There are 5 mass elements, which are respectively loading on nodes 1, 15, 19, 23, 36. High-speed shaft HS2 is divided to 34 units and 35 nodes. There are 5 mass elements, which are respectively loading on nodes $1,14,18,22,35$. Corresponding parameter of each particle is shown in Table 1 .

Table 1 Each nodes of 3 shafts correspond parameters $\left(\mathrm{kg} \cdot \mathrm{m}^{2}\right)$

\begin{tabular}{|c|c|c|c|c|c|c|}
\hline shaft & & 1 & 2 & 3 & 4 & 5 \\
\hline \multirow{2}{*}{ LS } & quality of particle & 572.0 & 15746.9 & 958.5 & - & - \\
\hline & Rotational Inertia & 25.3 & 21526.2 & 52.0 & & \\
\hline \multirow{2}{*}{ HS1 } & quality of particle & 360.0 & 102.1 & 28.297 & 102.1 & 427.7 \\
\hline & Rotational Inertia & 18.0 & 2.1 & 1.03 & 2.1 & 23.4 \\
\hline \multirow{2}{*}{ HS2 } & quality of particle & 848.8 & 110.6 & 31.485 & 110.6 & 1130.0 \\
\hline & Rotational Inertia & 38.4 & 2.5 & 1.4 & 2.5 & 106.1 \\
\hline
\end{tabular}

\section{Study on Dynamic Response of Coupling Rotor System}

Rotor of gear coupling system[4-8] have pair of gears so that the entire system subject gear tooth impact of the alternating excitation force, and then as the role of engagement lead to rotor speed of the shaft are not the same, make the system have unbalanced force caused by the emergence of multi-frequency excitation force. Because this presence of several special exciting force the response of the system become more complex, for the system of gear rotor the entire system response analysis is needed. This paper based on matlab programming and considered the effects of gyroscopic moment and supporting stiffness of the system.( Table 2 is the coupling system of the gear mesh stiffness of each shafts and the value of critical speed changing ) It is main study dynamic response of the coupling rotor system of the gear at the following two working conditions. (It's shown as table 3 " $\bigcirc$ "is adopted " $\times$ ”is not adopted.) 
Table 2 Critical speed of each shafts effect by meshing stiffness

\begin{tabular}{|c|c|c|c|c|c|c|c|c|}
\hline \multirow{3}{*}{ shaft } & \multirow{3}{*}{$\begin{array}{c}\text { mesh } \\
\text { stiffness } \\
(\mathrm{N} / \mathrm{m})\end{array}$} & \multicolumn{7}{|c|}{ Critical speed $(\mathrm{Hz})$} \\
\hline & & \multirow{2}{*}{$\begin{array}{l}\text { Axial } \\
\text { frequency }\end{array}$} & \multirow{2}{*}{$\begin{array}{c}\text { Coupling } \\
\text { frequency } \\
-\end{array}$} & \multirow{2}{*}{$\begin{array}{l}\text { Coupling } \\
\text { frequency } \\
\text { 二 }\end{array}$} & \multicolumn{2}{|c|}{ First order $\times(i=8.146)$} & \multicolumn{2}{|c|}{$\begin{array}{c}\text { Second } \\
\text { order } \times(i=8.146)\end{array}$} \\
\hline & & & & & $\begin{array}{l}\text { Backward } \\
\text {-precession }\end{array}$ & $\begin{array}{l}\text { forward- } \\
\text { precession }\end{array}$ & $\begin{array}{l}\text { backward- } \\
\text { precession }\end{array}$ & $\begin{array}{l}\text { forward- } \\
\text { precession }\end{array}$ \\
\hline \multirow{3}{*}{$\mathrm{LS}$} & $1 \times 106$ & 1.5344 & 4.3721 & 5.4492 & 36.9252 & 43.9330 & 48.5420 & 60.7797 \\
\hline & $1 \times 107$ & 1.5359 & 9.7331 & 14.5828 & 36.9329 & 43.9338 & 48.5461 & 60.7801 \\
\hline & $1 \times 108$ & 1.5360 & 29.2261 & 44.0875 & 37.0315 & 43.7109 & 48.6381 & 60.7846 \\
\hline \multirow{3}{*}{ HS1 } & $1 \times 106$ & 3.9283 & 4.3721 & 5.4492 & 61.7501 & 75.3724 & 69.2145 & 83.5379 \\
\hline & $1 \times 107$ & 5.0904 & 9.7331 & 14.5828 & 61.7519 & 75.3746 & 69.2155 & 83.5390 \\
\hline & $1 \times 108$ & 5.1071 & 29.2694 & 41.2637 & 61.7822 & 75.4002 & 69.2292 & 83.5524 \\
\hline \multirow{3}{*}{ HS2 } & $1 \times 106$ & 2.9077 & 4.3721 & 5.4492 & 54.5484 & 70.9463 & 74.6261 & 86.6166 \\
\hline & $1 \times 107$ & 3.7273 & 9.7331 & 14.2297 & 54.5491 & 70.9471 & 74.6269 & 86.6174 \\
\hline & $1 \times 108$ & 3.7406 & 29.2692 & 41.2229 & 54.5585 & 70.9556 & 74.6353 & 86.6262 \\
\hline
\end{tabular}

Table 3 Unbalance value and loading position of coupling system

\begin{tabular}{|c|c|c|c|c|c|c|c|c|c|}
\hline \multirow{3}{*}{$\begin{array}{c}\text { working } \\
\text { conditions }\end{array}$} & \multicolumn{9}{|c|}{ Unbalance of shaft segment $(\mathrm{g} \cdot \mathrm{mm})$} \\
\hline & \multicolumn{3}{|c|}{$\begin{array}{l}\text { LS (unbalance value and loading } \\
\text { position) }\end{array}$} & \multicolumn{3}{|c|}{ HS1 } & \multicolumn{3}{|c|}{ HS2 } \\
\hline & $\begin{array}{c}\text { left } \\
\text { end of } \\
\text { shaft }\end{array}$ & $\begin{array}{c}\text { Gear } \\
\text { Department }\end{array}$ & $\begin{array}{l}\text { right end } \\
\text { of shaft }\end{array}$ & $\begin{array}{c}\text { left } \\
\text { end of } \\
\text { shaft }\end{array}$ & $\begin{array}{c}\text { Gear } \\
\text { Department }\end{array}$ & $\begin{array}{c}\text { right } \\
\text { end of } \\
\text { shaft }\end{array}$ & $\begin{array}{c}\text { left } \\
\text { end of } \\
\text { shaft }\end{array}$ & $\begin{array}{c}\text { Gear } \\
\text { Department }\end{array}$ & $\begin{array}{c}\text { right } \\
\text { end of } \\
\text { shaft } \\
\end{array}$ \\
\hline & 57850.8 & 173552.5 & 41945.33 & 15625.6 & 52023.1 & 13872.4 & 35503.3 & 92786.6 & 29887.6 \\
\hline $\begin{array}{c}\text { working } \\
\text { condition } \\
-\end{array}$ & $\bigcirc$ & $x$ & $\bigcirc$ & $x$ & $x$ & $x$ & $x$ & $x$ & $x$ \\
\hline $\begin{array}{c}\text { working } \\
\text { condition } \\
\text { 二 }\end{array}$ & $x$ & $x$ & $x$ & $\bigcirc$ & $x$ & $\bigcirc$ & $x$ & $x$ & $x$ \\
\hline
\end{tabular}

For the working condition at one, amplitude-frequency characteristic curve of three shafts shown as Fig.5. In Fig. 5 (a) $\sim$ (d) are LS, HS1 and HS2 response of three shafts. Fig. 6(a) $\sim$ (b) are LS shaft of global response diagram and local response diagram, test points $1 \sim 5$ are left end of shaft, gear, right end of shaft, nodes of left support and right support. From Fig.5 (a) can be seen that for low-speed shaft, only within $50 \mathrm{rpm}$, there is greater amplitude of vibration. Fig.5 (b) is the result of vibration amplitude after magnified handling between $0 \sim 50 \mathrm{rpm}$.From the figure can be seen that rotor speed position at $7.5 \mathrm{rpm}, 13.5 \mathrm{rpm}, 16.5 \mathrm{rpm}$ and $18.5 \mathrm{rpm}$ have large amplitude, which amplitude in 7.5rpm and 13.5 are more obvious. The reason was mainly due to the mesh frequency generated when the gear meshing. (Mesh frequency is the product of the current speed and gear teeth of the shaft, in figure it is: $7.5 \times 334=2505 \mathrm{rpm}$, this digital is very close to the first order critical speed of low speed shaft. So it is considered that, when LS rotating speed at 7.5rpm, low-shaft has appeared resonance phenomenon, it cause low-speed shaft vibration increase. For $13.5 \times 334=4509 \mathrm{rpm}$, it is very close to an order critical speed of low speed shaft, so there is appear larger peak also ). The response of high speed shaft HS1 is shown as Fig. 5(c). Speed between 
$114 \mathrm{rpm}$ and $1071 \mathrm{pm}$ appear larger vibration amplitude, in which the vibration of frequency $114 \mathrm{rpm}$ is caused by LS shaft frequency of 13.5rpm. $(110 /(334 / 41)=13.5$, of which 334 and 41 are the teeth numbers of a pair of gears). For the frequency of $1071 \mathrm{rpm}$ the vibration amplitude is caused by meshing stiffness of gear $(1071 \times 41=43911 \mathrm{rpm}$, of which 41 is the teeth number of HS1).

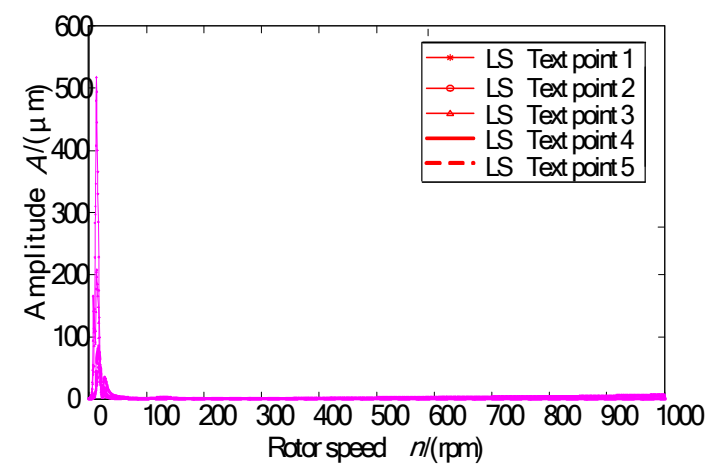

(a) Global response curve of LS

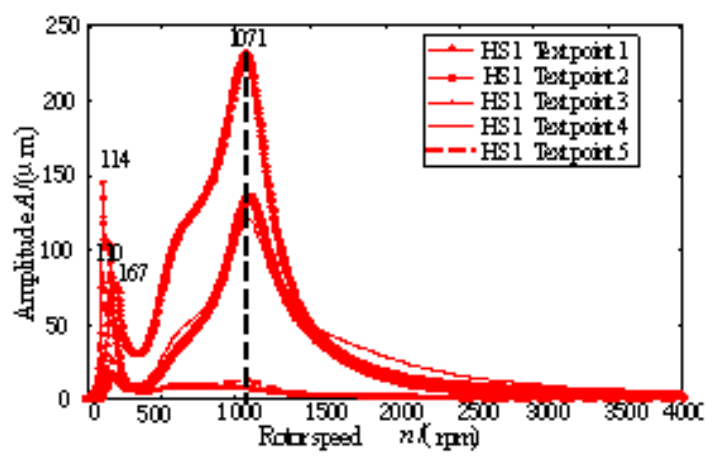

(c) Global response curve of HS1

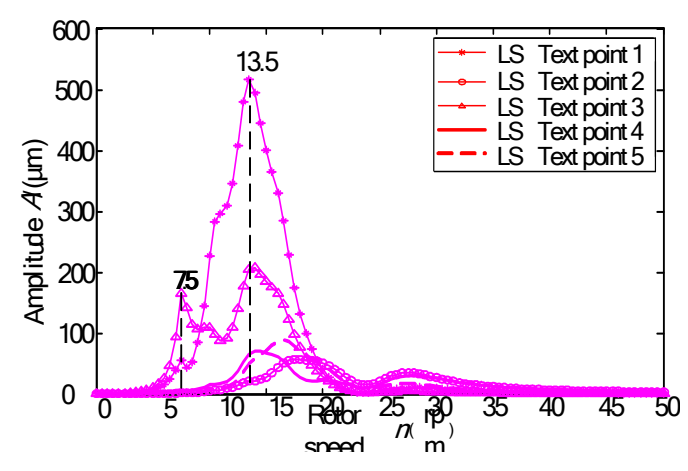

(b) Partial response curve of LS

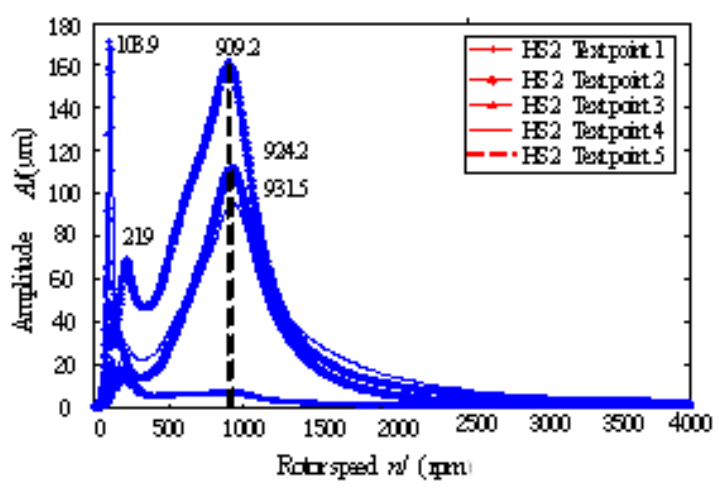

(d) Global response curve of HS2

Fig. 5. Amplitude-frequency characteristic curve of HS at wording condition one

For the working condition two amplitude-frequency characteristic curve of coupling system shown as Fig.6. In Fig.6(a) $\sim(d)$ are LS, HS1 and HS2 response of three shafts. Fig. (a) $\sim(d)$ are LS shaft of global response diagram and local response diagram, test points $1 \sim 5$ are left end of shaft, gear, right end of shaft, nodes of left support and right support. From Fig.6 can be seen that low-speed shaft same as working condition one. From the figure can be seen that rotor speed position at $7.5 \mathrm{rpm}, 13.5 \mathrm{rpm}, 16.5 \mathrm{rpm}$ and $8.5 \mathrm{rpm}$, there are large amplitude occur. For HS1 response shown in Fig.6 (c) it is induced by new frequency ratio, which is caused by meshing stiffness of system, just as working condition one.

From Fig. 6(d) can be seen that because unbalanced force is added to the HS1, the resonance is aroused in the first two order critical speed and it's not obviously display in LS and HS2.

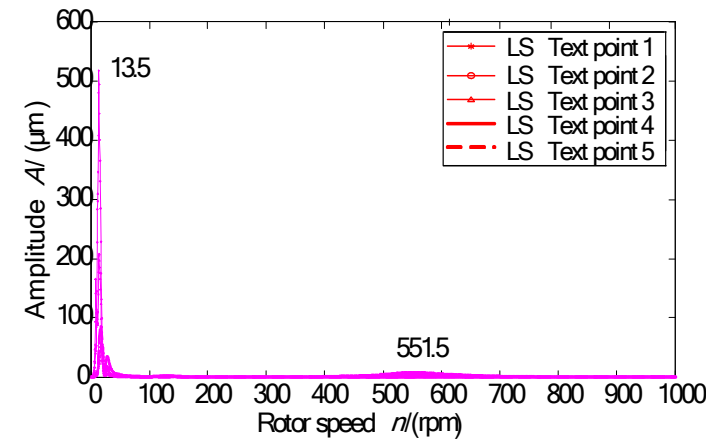

(a) Global response curve of LS

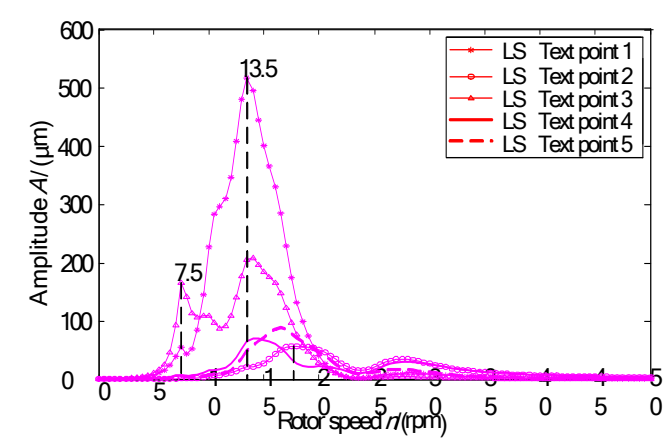

(b) Partial response curve of LS 




(c) Global response curve of HS1

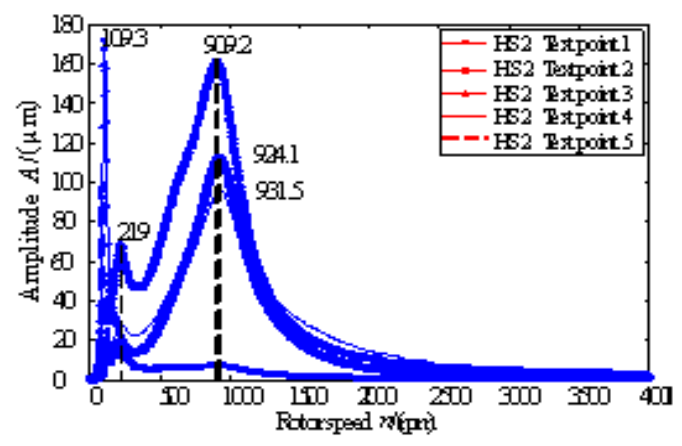

(d) Global response curve of HS2

Fig. 6. Amplitude-frequency characteristic curves

\section{Conclusion}

In consider of coupling effect produced by gear meshing and supporting stiffness changed under speed variation, a dynamic model of a rotor system of assembled compressor is established. Conclusions are obtained as follow:

(1) For low-speed shaft, there are several large vibration amplitude occurred, which is mainly caused by the mesh frequency at a very low speed

(2) For high-speed shaft, there are two large vibration amplitude occurred at the rotor speed of $114 \mathrm{rpm}$ and $1071 \mathrm{pm}$, which is mainly caused by new frequency ratio of system. The new frequency ratio is induced by meshing stiffness. Because unbalanced force is added to the HS1, the resonance is aroused in the first two order critical speed and there are not obviously display in LS and HS2.

\section{Acknowledgements}

We are grateful to the China Natural Science Funds (NSFC, Grant No. 50975045) for providing financial support for this work.

\section{References}

[1] Kubur, M, Kahraman, A, Zini, D. M. and Kienzle, K. (2004): Dynamic Analysis of a Multi-Shaft Helical Gear Transmission by Finite Elements: Model and Experiment, ASME J. Vibr. Acoust, 126, pp. 398-406.

[2] NICHOLAS J C , GUNTER E J, ALLAIRE P E. Stiffness and damping coefficients for the five-pad tilting-pad bearing, ASLE,1979, 22(2):113-124.

[3] Lee A S, Kima B O, Kimb Y C. A finite element transient response analysis method of a rotorbearing system to base shock excitations using the state-space newmark scheme and comparisons with experiments. Journal of Sound and Vibration, 2006, 297(3-5): 595-615.

[4] Li G Y, Qin D T. Dynamics analysis of gas turbine gear coupling rotor system. China Mechanical Engineering, 2010, 21(14): 1655-1660.

[5] Qin D T, Qian E, Shi W K. Dynamics Characteristics of gas turbine gear coupling rotor system. Journal of Chongqing University, 2010, 33(1): 19-24.

[6] Pang H, Fang Z D, Ou W L. Vibration Characteristic Analysis of multiple parallel gear coupling rotor system. Vibration and Shock, 2007, 26(6): 21-25.

[7] Li M, Yu L, Analysis of the coupled lateral torsional vibration of a rotor-bearing system with a misaligned gear coupling. Journal of Sound and vibration, 2001, 243(2): 283-300.

[8] Zhang S H, Shi S H, Qiu D M. A Nonlinear Model for Dynamic Analysis of a Geared Rotor-Bearing System. Mechanical Science and Technology, 2001, 20(2): 191-193. 